
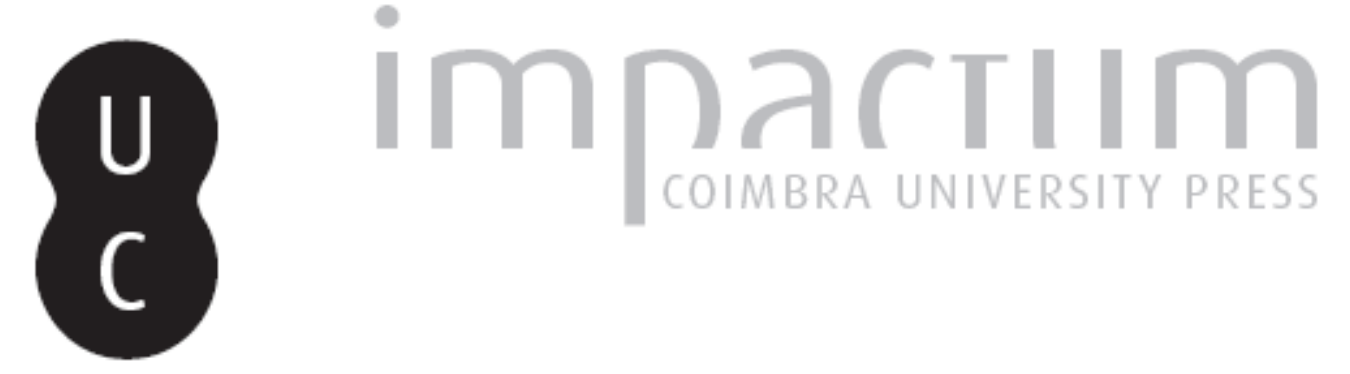

\title{
[Recensão a] ALEXANDER JAMES DALLAS, An Exposition of the Causes and Character of the War. An Annotated Edition by H. G. Callaway
}

Autor(es): $\quad$ Pires, Edmundo Balsemão

Publicado por: Faculdade de Letras da Universidade de Coimbra, Instituto de Estudos

URL

persistente:

Filosóficos

DOI: DOl:http://dx.doi.org/10.14195/0872-0851_40_11

Accessed : $\quad$ 26-Apr-2023 16:22:06

A navegação consulta e descarregamento dos títulos inseridos nas Bibliotecas Digitais UC Digitalis, UC Pombalina e UC Impactum, pressupõem a aceitação plena e sem reservas dos Termos e Condições de Uso destas Bibliotecas Digitais, disponíveis em https://digitalis.uc.pt/pt-pt/termos.

Conforme exposto nos referidos Termos e Condições de Uso, o descarregamento de títulos de acesso restrito requer uma licença válida de autorização devendo o utilizador aceder ao(s) documento(s) a partir de um endereço de IP da instituição detentora da supramencionada licença.

Ao utilizador é apenas permitido o descarregamento para uso pessoal, pelo que o emprego do(s) título(s) descarregado(s) para outro fim, designadamente comercial, carece de autorização do respetivo autor ou editor da obra.

Na medida em que todas as obras da UC Digitalis se encontram protegidas pelo Código do Direito de Autor e Direitos Conexos e demais legislação aplicável, toda a cópia, parcial ou total, deste documento, nos casos em que é legalmente admitida, deverá conter ou fazer-se acompanhar por este aviso.

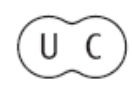




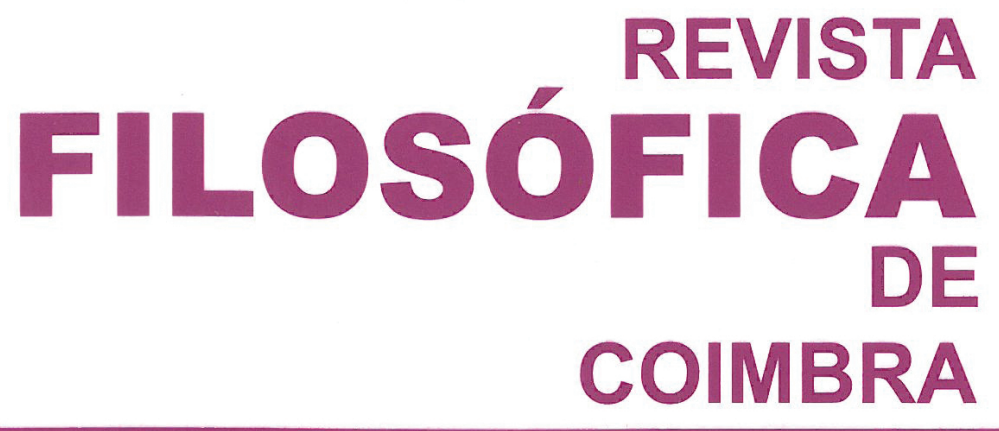

vol. 20 - número 40 - outubro 2011

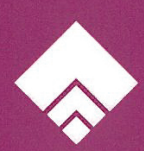


ALEXANDER JAMES DALLAS, An Exposition of the Causes and Character of the War. An Annotated Edition by H. G. Callaway, Edinburgh, Dunedin Academic Press, 2011.

A uma distância de cerca de duzentos anos a reedição do opúsculo de Alexander James Dallas, Uma Exposição sobre as Causas e o Carácter da Guerra (terminado em Fevereiro de 1815), recentemente publicada pela editora Dunedin, permite-nos aceder a um tema do pensamento político moderno e a alguns episódios históricos de relevância internacional.

Nascido em 1759, na Jamaica, A. James Dallas foi um conhecedor da política externa e interna dos Estados Unidos por dentro, tendo ocupado vários cargos na Administração da jovem República Americana, desde o de Secretário da Commonwealth da Pennsylvania até ao cargo de Secretário do Tesouro dos Estados Unidos sob indicação do Presidente James Madison em 1814.

Os episódios históricos que motivaram o texto de A. J. Dallas situam-se no período da "Guerra da Independência" e centram-se particularmente na guerra entre os Estados Unidos e a Inglaterra (entre 1812 e 1814). Na narração destes acontecimentos reflectem-se impressões e testemunhos sobre as políticas imperiais da França, de Inglaterra, da Espanha e também há referências a Portugal. Mas o opúsculo é antes de tudo um exemplo de retórica da guerra.

O tema que serve de integração geral à narrativa e argumentos do autor é o da justificação da declaração de guerra por parte dos Estados Unidos à Inglaterra. Não se deve considerar esta "exposição" um documento doutrinário sobre a "guerra justa" mas antes um texto argumentativo situado nos acontecimentos que o suscitaram e reagindo a eles.

A grande variedade de situações envolvidas na "Guerra da Independência" que tiveram como protagonistas a Inglaterra e os Estados Unidos são objecto de descrições e juízos e motivam abordagens de temas muito diferentes entre si como as ideias sobre o comércio entre as nações, o mare liberum, a crítica da ingerência nos assuntos internos dos estados, a defesa da liberdade de escolha de nacionalidade quando isso pode suceder ou as observações sobre a diferença entre selvajaria e civilização e o papel dos índios na guerra.

O conhecimento da história dos conflitos navais entre barcos americanos e navios ingleses é a base da linha argumentativa que leva o autor a legitimar do lado americano o jus ad bellum. Os britânicos consideravam justificado mandar parar em pleno mar os barcos de transporte americanos para revistas e inspecções sob pretexto que neles viajassem cidadãos britânicos procurados. Estas circunstâncias são consideradas injustificadas, provocatórias e geradoras de um clima de desconfiança, para além de constituirem ingerência.

Dos episódios que datam do período da guerra o autor refere a aliança entre os britânicos e algumas populações índias e a conduta na guerra destas últimas em comentários sobre o jus in belo que não deixam dúvidas sobre a diferença 
entre selvajaria e civilização e sobre a qualificação a atribuir ao comportamento dos britânicos no injusto tratamento de prisioneiros de guerra ou, mais grave, nos abusos dos índios nas razias, pilhagens e assassinatos de civis.

No que diz respeito às motivações legítimas para os Estados Unidos fazerem guerra o autor defende que é um pretenso direito mandar parar navios sob pavilhão americano, ou de outra nação, em pleno mar, para inspecções. Considera que se trata de uma exigência que apenas decorre de leis municipais inglesas sem possível aplicação no "direito das gentes" ou no comércio marítimo entre as nações (p. 39). O facto de os ingleses agirem no mar segundo as suas normas domésticas faz com que este impedimento à livre navegação se torne numa ingerência nos assuntos de outros povos e nações. O princípio da livre disposição soberana fica em causa com a entrada de militares ingleses em navios americanos, mas também se põe em questão o direito de navegar sem impedimentos em alto mar, que o autor designa por "highway of nations" (p. 41). É a propósito que A. J. Dallas retoma a discussão em redor do mare liberum / mare clausum e claramente defende a tese Grotiana.

Outra das exigências britânicas era a de poder tutelar o comportamento e as escolhas de determinados cidadãos ingleses, em solo americano ou no mar, sob pavilhão americano, em condições de dupla nacionalidade. Assim, os britânicos punham em causa o direito à naturalização americana nas condições em que a lei americana o autorizava, o que era outra forma de ingerência. Contra isto o governo americano sustentava o direito à livre navegação com respeito do direito ao uso e comando de pavilhão, o direito de livre comércio marítimo e à livre naturalização, quando ela pudesse ocorrer, ao abrigo das leis domésticas.

As violações destes princípios básicos forçariam qualquer nação a acções de defesa dos seus interesses, argumenta A. J. Dallas.

A reacção britânica à declaração de guerra do Congresso Americano assinada pelo presidente James Madison, a 18 de Junho de 1812, foi a de uma inversão do culpado e da culpa: os americanos passaram a agressores. Na narrativa de A. J. Dallas mostra-se com clareza em que consistiu esta inversão na retórica britânica sobre a guerra. $\mathrm{O}$ interessante é que nesta mesma retórica entra o papel atribuído às populações índias que são chamadas a aliar-se aos britânicos contra o poder opressor da República Americana.

Nesta reconstrução da retórica inglesa relemos aspectos que não perderam actualidade. Um deles é o do expansionismo dos americanos. É curioso verificar como foram os ingleses, um dos maiores impérios colonais da época, que utilizaram o argumento possivelmente pela primeira vez. Segundo eles, a ambição territorial da República Americana no mar e na vizinhança do seu próprio território seria desmedida e a guerra contra a Grã-Bretanha ditada por um desejo de grandeza e de conquista (p. 77).

Ilustrando os contra-argumentos Uma Exposição identifica vários exemplos em que demonstra o carácter pacífico dos americanos e o seu respeito pelas 
regras civilizadas do comportamento na guerra. Por fim, na parte final do opúsculo, como complemento da regra do respeito mútuo da soberania dos estados, é feita a defesa do princípio do "equilíbrio do poder" das potências de expressão marítima como forma de manter uma paz duradoura. Assim se retoma um conceito conhecido desde o século XVII para exprimir a ideia de uma regulação das relações internacionais pela antecipação contrafactual das acções dos adversários, que perdurará até à Guerra Fria.

Na presente edição da Exposição de A. J. Dallas acrescentou-se uma introdução de carácter histórico do editor, H. G. Callaway, notas explicativas, três apêndices contendo os tratados internacionais de Paris, o chamado tratado de Jay e o tratado de Ghent. Uma cronologia dos principais acontecimentos da época e uma bibliografia seleccionada terminam o livro. Trata-se de um documento importante para a compreensão da retórica da guerra, em geral, e para a ilustração de temas decisivos da "Guerra da Independência" dos Estados Unidos. Interessará, seguramente, os estudiosos de temas de Filosofia Política, História Moderna e Relações Internacionais.

Edmundo Balsemão Pires

GOMÈZ-HERAS, José M. ${ }^{\text {a }}$ G. ${ }^{\text {a }, ~ E n ~ a r m o n i a ~ c o m ~ l a ~ n a t u r a l e z a . ~ R e c o n s t r u c-~}$ cíon medioambiental de la filosofia, Biblioteca Nueva, Madrid, 2010.

Numa época em que o termo crise se empobrece e gasta diariamente na omnipresença das preocupações financeiras, o texto em apreço de Gomèz-Heras, conhecido catedrático jubilado da Universidade de Salamanca, tem o mérito de colocar os assuntos em perspectiva: lembra-nos que as preocupações pela oikos não podem realmente obnubilar o modelo ecológico e ambiental de crise, ou seja - o que é o mesmo - não podem aquelas preocupações dispensar um modo de pensar alternativo capaz de responder aprofundadamente à complexidade dos problemas do mundo contemporâneo (cf., por exemplo, p. 25). Pensar hoje a vida e o sentido continua a exigir que se interrogue a complexidade do sentido propriamente humano de morada; mas este sentido, justamente, tem múltiplas e complexas dimensões às quais apenas um esforço filosófico vigoroso, forjado no horizonte de um paradigma ambiental, pode dar resposta. Neste contexto a obra de Gomèz-Heras pretende ser "um contributo para tal empresa" árdua que é a de compreender o presente do nosso modo de pertença ao mundo e aos outros a partir de uma reflexão tocada pela vida e pela natureza e orientada pelos valores que estas podem motivar. E esse contributo será especificamente filosófico: "nada mais. Mas também nada menos" (p. 35). Porque, de facto, não é pouco o que esta obra tem para oferecer. 